\title{
Growth and Tolerance of Pleurotus ostreatus at Different Selenium Forms
}

\author{
Marliane de Cássia Soares da Silva ${ }^{1}$, José Maria Rodrigues da Luz ${ }^{2}$, Ana Paula S. Paiva ${ }^{1}$, \\ Daniele Ruela Mendes ${ }^{1}$, Alexandrina A. C. Carvalho ${ }^{3}$, Juliana Naozuka ${ }^{4} \&$ Maria Catarina Megumi Kasuya ${ }^{1}$ \\ ${ }^{1}$ Departamento de Microbiologia, Universidade Federal de Viçosa, Viçosa, MG, Brazil \\ ${ }^{2}$ Programa de Pós-Graduação Multicêntrico na Área de Bioquímica e Biologia Molecular, Escola de Enfermagem \\ e Farmácia, Universidade Federal de Alagoas, Maceió, AL, Brazil \\ ${ }^{3}$ Departamento de Química Fundamental, Instituto de Química, Universidade de São Paulo, SP, Brazil \\ ${ }^{4}$ Departamento de Química, Universidade Federal de São Paulo, Diadema, SP, Brazil \\ Correspondence: Maria Catarina Megumi Kasuya, Departamento de Microbiologia, Universidade Federal de \\ Viçosa, Viçosa, Minas Gerais, 36570-000, Brazil. Tel: 55-313-899-2970. E-mail: mkasuya@ufv.br
}

Received: August 30, 2018

doi:10.5539/jas.v11n2p151

\begin{abstract}
Selenium is an important element in physiological and metabolic processes. Due to low Se concentration in most of the soils, strategies as enrichment and biofortification have been used to increase its incorporation in food. The fungus has capacity to absorb, accumulate and transform Se inorganic into organic compounds. However, the concentration and chemical forms of Se used for enrichment can affect the mycelial growth and mushrooms production. Thus, the aim of this study was to analyze the capacity of Pleurotus ostreatus in absorb, accumulate and tolerate growing concentrations of different Se chemical forms. In the disc of agar with mycelium was added $20 \mathrm{~mL}$ of PDA medium and Se concentration $\left(0-200 \mathrm{mg} \mathrm{L}^{-1}\right)$ in the forms of sodium selenite, sodium selenate or selenomethionine (SeMet). The greatest inhibition of mycelial growth and biomass production were observed in highest Se concentration. Regardless of the Se level, SeMet and sodium selenite were more harmful to the $P$. ostreatus growth than sodium selenate. However, the highest Se accumulation in the mycelium was observed in culture medium with sodium selenite. Thus, Se supplementation in the forms of sodium selenite was more indicated to enrichment of $P$. ostreatus mushrooms than sodium selenate and SeMet.
\end{abstract}

Keywords: fungal biomass, selenium inorganic, selenium organic, mushrooms, mycelium growth rate

\section{Introduction}

Selenium ( $\mathrm{Se}$ ) is an essential element to human health. It has antioxidant function and is an immunosystem modulator, and have participation in biosynthesis of ubiquinone, ATP and proteins (Viaro et al., 2001). In the case of chronic diseases such as cancer, cardiovascular, oxidative stress or inflammatory conditions, the Se can act as protective element (Rayman, 2000). However, the Se concentration in food is low (Ferreira et al., 2002). Therefore, enrichment or biofortification have been strategies used to increase the concentration and availability of this element in food (da Silva et al., 2012; Silva et al., 2010; Solovyev et al., 2018).

The Se-enrichment of mushrooms using agriculture residue has been an alternative for accumulation of Se and production of organic Se (da Silva et al., 2012; Falandysz, 2008; Fang et al., 2018; Hu et al., 2018; Nunes et al., 2012; Solovyev al., 2018). Furthermore, mushrooms are much appreciated food, which contain protein, essential aminoacids, fibers, fatty acid and minerals (Manzi et al., 1999). This food is indicated to feeding of people with malnutrition problem (Kane et al., 2017).

The high Se concentration can inhibit the mycelial growth and production of Pleurotus ostreatus mushrooms (Da Silva et al., 2012, 2013). Therefore, for Se-enrichment of mushrooms it would be interesting to investigate the effect of different Se chemical forms on growth and morphology of mycelium of $P$. ostreatus and determine the best concentration to be used for enrichment. Furthermore, P. ostreatus is one of the most produced and consumed mushrooms in the world (Azevedo et al., 2012; Furlani \& Godoy, 2007) that shows its economic and nutritional importance. 
Thus, the aim of this study was to analyze the capacity of Pleurotus ostreatus in absorb, accumulate and tolerate growing concentrations of different chemical forms of Se.

\section{Material and Method}

\subsection{Microorganisms}

The isolate of P. ostreatus (PLO 02) of the Department of Microbiology of the Federal University of Viçosa/BIOAGRO, MG, Brazil was used in this study. This isolate was also used in enrichment of mushrooms with selenium, lithium and zinc (da Silva et al., 2012; de Assunção et al., 2012; Vieira et al., 2013).

For inoculum production, this isolate was grown in a Petri dish containing potato dextrose agar (PDA) culture medium, $\mathrm{pH} 5.8$, and incubated at $25 \pm 2{ }^{\circ} \mathrm{C}$ for seven days.

\subsection{Enrichment of P. ostreatus}

Two assays were done. In the first test, $P$. ostreatus was inoculated in PDA media containing 12.5; 25; 50 or 75 $m g \mathrm{~L}^{-1}$ of $\mathrm{Se}$, as sodium selenite $\left(\mathrm{Na}_{2} \mathrm{SeO}_{3}\right)$, sodium selenate $\left(\mathrm{Na}_{2} \mathrm{SeO}_{4}\right)$ or selenomethionine (SeMet). These concentrations were obtaining on previous studies (da Silva et al., 2012, 2013; Silva et al., 2010). In the second, the fungus was inoculated in PDA with $25,50,100,150$ and $200 \mathrm{mg} \mathrm{L}^{-1}$ of $\mathrm{Se}$, as $\mathrm{Na}_{2} \mathrm{SeO}_{4}$. In both tests, the control was PDA without Se. The cultures were incubated for seven days at $25 \pm 2{ }^{\circ} \mathrm{C}$.

\subsection{Mycelial Growth Velocity and Biomass}

The mycelial growth was verified by taken two measurements, perpendicular to each other, at seventh days. The growth rate was calculated by the ratio between colony diameter and time of incubation. This diameter was measured by taken two measurements, perpendicular to each other at seven days.

To evaluate the mycelium dry biomass, all the content of Petri dish was transferred to a flask with $200 \mathrm{~mL}$ of distilled water and boiled, in microwave oven, to liquefy agar (Da Silva et al., 2012), followed by filtration and rinsing in distilled water. The retained mycelium was dried at $60^{\circ} \mathrm{C}$, until constant weight.

\subsection{Hyphae Diameter and Distance Between Septa}

Theses parameters were measured after stained with calcofluor and observed under epifluorescence microscopy (Olympus BX 50). The images were capture by digital camera FUJIX HC-300Z and processed with the software Image Pro Plus.

\subsection{Selenium Determination in Mycelium}

All solutions were prepared from analytical reagent grade chemicals using high-purity deionized water obtained from a Milli-Q water purification system (Millipore, Belford, USA). Selenium analytical solution $\left(\mathrm{Na}_{2} \mathrm{SeO}_{3}\right)$ of $1000 \mathrm{mg} \mathrm{L}^{-1}$ was used as standard and its determination by Graphite furnace atomic absorption spectrometry (GF AAS). In the last case, a volume of $10 \mu \mathrm{L}$ of chemical modifier solution of $5 \mathrm{mg}$ of palladium and $3 \mathrm{mg}$ of magnesium was co-injected with $10 \mu \mathrm{L}$ of samples or analytical solutions into the graphite furnace.

The acid digestion of mycelium was done using $65 \%(\mathrm{v} / \mathrm{v})$ nitric acid $\left(\mathrm{HNO}_{3}\right)$ and $30 \%(\mathrm{v} / \mathrm{v})$ hydrogen peroxide $\left(\mathrm{H}_{2} \mathrm{O}_{2}\right)$ from Merck (Darmstadt, Germany). A buffer solution of $0.2 \mathrm{~mol} \mathrm{~L}^{-1}$ Tris/ $\mathrm{HCl}$ was prepared by dissolving Tris(hydroxymethyl)aminomethane (USB Corporation) in deionized water and adjusting the $\mathrm{pH}$ to 7.5 with chloridric acid (Merck).

The mycelium of $P$. ostreatus were subjected to acid digestion in a microwave oven, using diluted oxidant mixture $\left(2.0 \mathrm{~mL} \mathrm{HNO}_{3}+1.0 \mathrm{~mL} \mathrm{H}_{2} \mathrm{O}_{2}+3.0 \mathrm{~mL} \mathrm{H}_{2} \mathrm{O}\right)$. The microwave heating program presented four steps (Temperature/1C; ramp/min; hold/min): $1(140 ; 5 ; 1), 2(180 ; 4 ; 5), 3(200 ; 4 ; 10), 4(0 ; 0 ; 20)$. The final volume was $15 \mathrm{~mL}$.

Selenium concentration in the digested samples was determined (GF AAS) according to Silva et al. (2010).

\subsection{Statistics}

The experiment was a completely randomized design, with three replicates. The assay was for twice. The data were subjected to analysis of variance and mean values were compared by Tukey's test $(p<0.05)$.

\section{Results and Discussion}

Selenium affect the color of colony and the mycelial growth rate (Figures 1 and 2). The change of color from white to orange (Figure 1), mainly in culture medium with sodium selenite, may be due to the precipitation of selenium elemental. In anaerobic conditions, it occurs the reduction of selenite in selenium (Sylvia et al., 1999). Therefore, during $P$. ostreatus growth in the culture medium may have occurred the anaerobiosis microsites that favor the selenite reduction. Furthermore, the changing in the color of colony is due to metabolites production in 
culture medium with selenium (Da Silva et al., 2013). Thus, studies for identification of theses metabolites are important for understand the transformation of selenium inorganic to organic forms by the fungus.

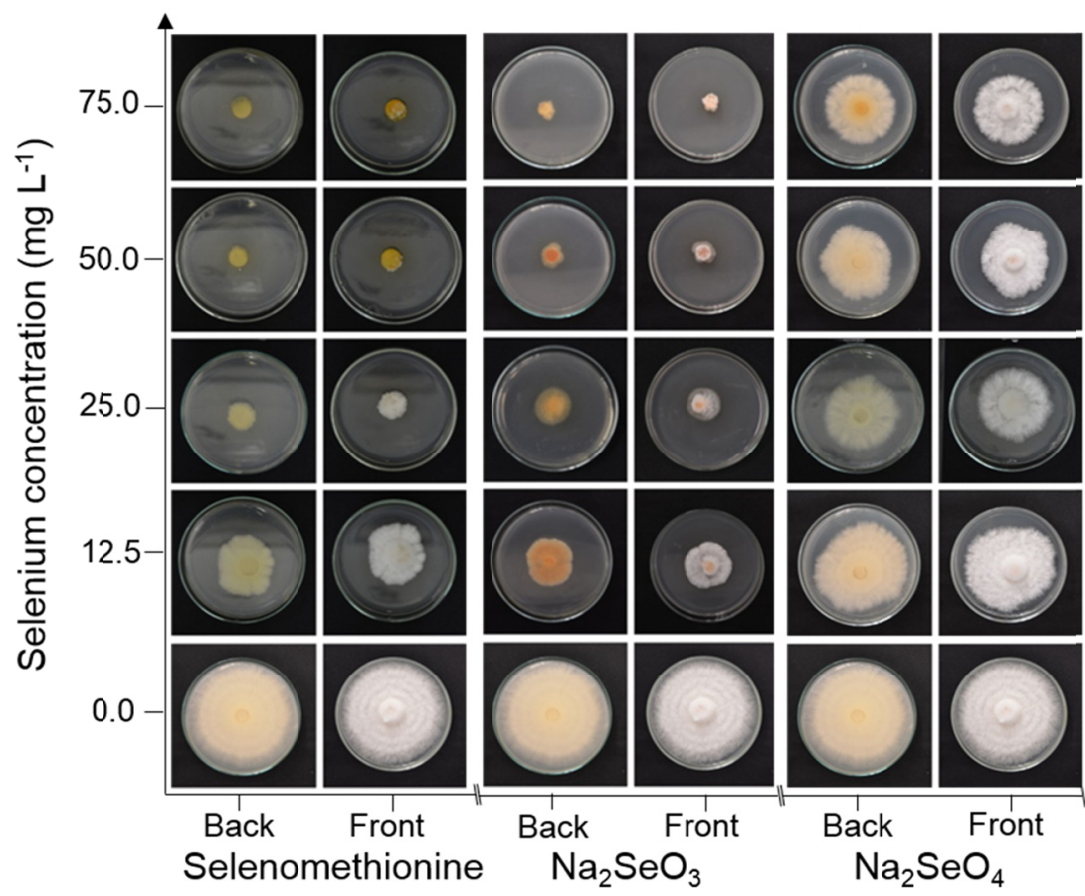

Figure 1. Micelyal growth of Pleurotus ostreatus (Plo 02) in PDA medium with selenomethione (SeMet), sodium selenite $\left(\mathrm{Na}_{2} \mathrm{SeO}_{3}\right)$ and sodium selenate $\left(\mathrm{Na}_{2} \mathrm{SeO}_{4}\right)$ in differ selenium concentration $\left(0,12.5,25,50\right.$ and $\left.75 \mathrm{mg} \mathrm{L}^{-1}\right)$

The inhibition in mycelium growth rate may be due to the selenium oxidation (Figures 1 and 2). Selenomethionine and selenite were more toxic for P. ostreatus than selenate (Figure 2). These different effects on the mycelial growth and biomass may be due to the metabolic mechanisms of Se forms (Sors et al., 2005).

We also observed strong odor in culture medium with selenite during fungus growth that may be due to the production of dimethyl selenide [ $\left.\left(\mathrm{CH}_{3}\right)_{2} \mathrm{Se}\right]$ (Sylvia et al., 2004; Amouroux et al., 2000). According to Zhang and Chasteen (1994), the methylation of selenium inorganic by microorganism produce volatile organic compounds that are less toxic than inorganic forms. Thus, the $\left[\left(\mathrm{CH}_{3}\right)_{2} \mathrm{Se}\right]$ production by fungus can be a detoxification mechanism (Milovanovic et al., 2014; Zhang \& Chasteen, 1994). Therefore, more studies have be done to evaluate this mechanism. 


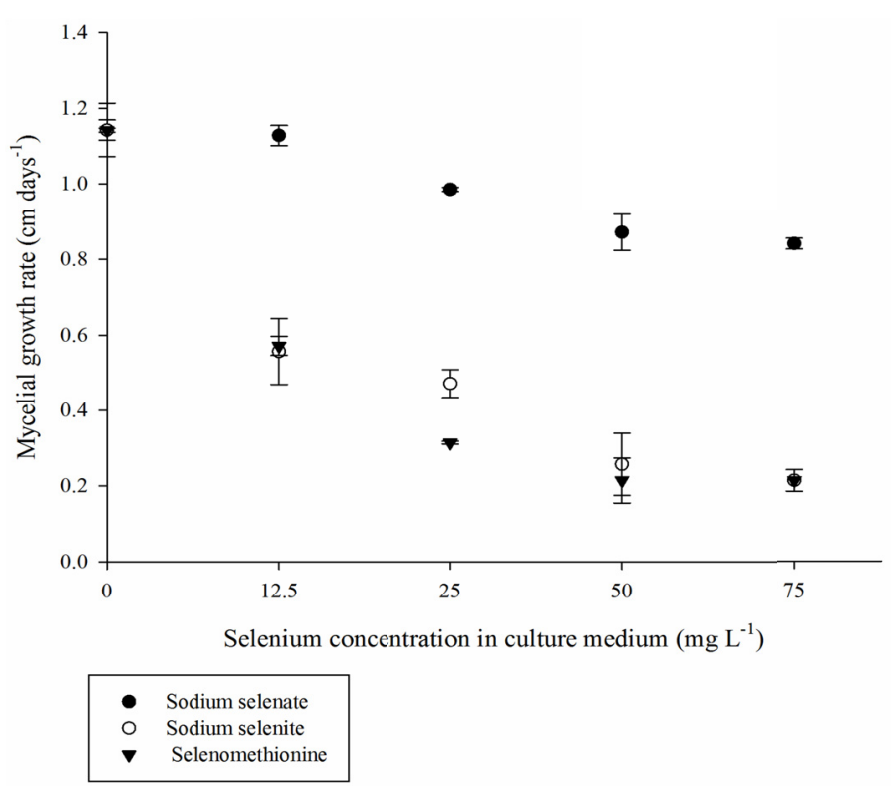

Figure 2. Mycelial growth rate of Pleurotus ostreatus (Plo 02) in PDA medium with selenomethione (SeMet), sodium selenite $\left(\mathrm{Na}_{2} \mathrm{SeO}_{3}\right)$ and sodium selenate $\left(\mathrm{Na}_{2} \mathrm{SeO}_{4}\right)$ in differ selenium concentration

$\left(0,12.5,25,50\right.$ and $\left.75 \mathrm{mg} \mathrm{L}^{-1}\right)$

Similar to mycelial growth rate, the biomass decreased in function of increasing of Se concentration and oxidation state (Figure 3). The biomass with selenate was not affected until $25 \mathrm{mg} \mathrm{L}^{-1}(\mathrm{p}<0.05)$, while to others chemical forms the biomass was affected by all tested selenium concentrations (Figure 3). Da Silva et al. (2013) observed that the increase in Se concentration in form of sodium selenite decreased form 2.5 at 8 folds in fungal biomass.

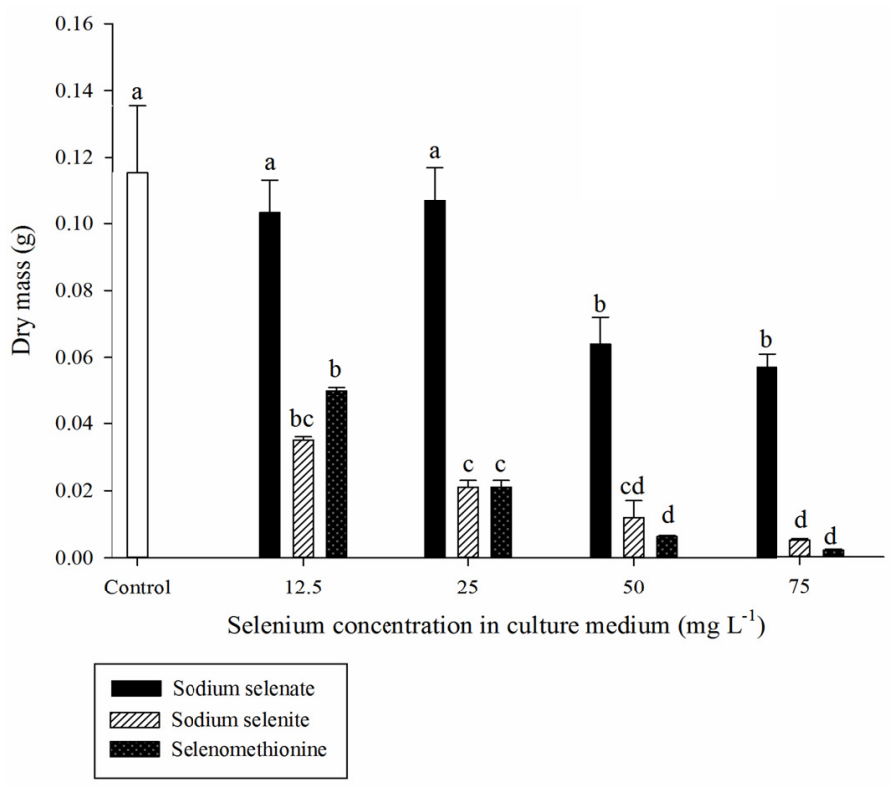

Figure 3. Dry mass (Biomass) of Pleurotus ostreatus (Plo 02) in PDA medium with selenomethione (SeMet), sodium selenite $\left(\mathrm{Na}_{2} \mathrm{SeO}_{3}\right)$ and sodium selenate $\left(\mathrm{Na}_{2} \mathrm{SeO}_{4}\right)$ in differ selenium concentration $(0,12.5,25,50$ and $\left.75 \mathrm{mg} \mathrm{L}^{-1}\right)$. Means followed by different letters differ at Tukey's test $(\mathrm{p}<0.05)$ 
This is the first study using selenomethionine in mycelial growth of $P$. ostreatus. The aim of the addition of this amino acid was to analyze the ability of this fungus to incorporate it directly into selenoprotein. The production of selenium organic by microorganisms have been shown (Da Silva et al., 2012; de Assunção et al., 2014; Fang et al., 2018; Hu et al., 2018; Milovanovic et al., 2014). Furthermore, the selenium inorganic was added to proteins by replacing sulfur (Rayman, 2008).

To quantify selenium was used the mycelium produced in culture medium with selenite and selenate in 12 and $25 \mathrm{mg} \mathrm{L}^{-1}$ of Se due to highest mycelial growth rate and biomass production (Figures 2-4). The trace concentration of selenium in the control can be derived from the reagents, PDA or water (Figure 4).

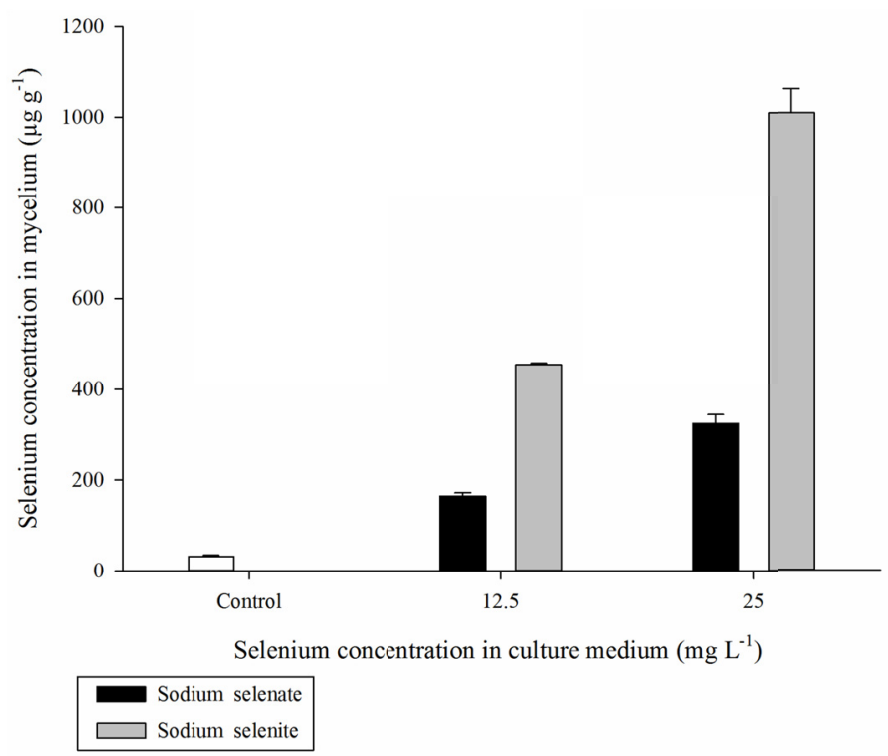

Figure 4. Selenium concentration in Pleurotus ostreatus (Plo 02) mycelium that was growth in PDA medium with sodium selenite $\left(\mathrm{Na}_{2} \mathrm{SeO}_{3}\right)$ and sodium selenate $\left(\mathrm{Na}_{2} \mathrm{SeO}_{4}\right)$ in differ selenium concentration $\left(0,12.5\right.$ and $\left.25 \mathrm{mg} \mathrm{L}^{-1}\right)$

The accumulation of selenium in the mycelium was higher in $P$. ostreatus grown with selenite than selenate (Figure 4), because the incorporation of selenium in protein is faster as selenite than selenate (Rayman 2008). Therefore, for production of selenoprotein it is important to choose the fungal species/isolate, the chemical form, and the maximum concentration of selenium, which allows its growth, as well as the absorption, accumulation and biotransformation. The capacity of P. ostreatus and Lentinula edodes in absorb, accumulate and incorporate Se inorganic in mushrooms have been shown when these fungi were grown in agroindustrial residues containing different sodium selenite levels (Da Silva et al., 2012; Hu et al., 2018; Nunes et al., 2012; Silva et al., 2010; Solovyev et al., 2018).

P. ostreatus had small reduction in mycelial growth rate (Figure 2) and in biomass (Figure 3) in culture medium with at $75 \mathrm{mg} \mathrm{L}^{-1}$ of Se in form of selenate. This shows the higher potential of this fungus in grow in substrate containing high selenium concentration in form of selenate than in form of sodium selenite. Therefore, it was analyzed the effect of selenium concentration of 25 at $200 \mathrm{mg} \mathrm{L}^{-1}$ in the selenate forms on hyphae diameter and septa distance (Figures 5 and 6). These results are important for clarify the mechanism of tolerance of $P$. ostreatus at high selenium concentration.

The addition of selenate changed only septa distance and it was not observed changes significant entre hyphae diameter (Figures 5 and 6). Da Silva et al. (2013) also observed the decreased septa distance in the P. ostreatus and Pleurotus eryngii in culture medium containing sodium selenite.

The decrease of septa distance not was proportional the Se concentration (Figure 5) that show the tolerance of $P$. ostreatus at the high Se concentration. Furthermore, none changes in hyphae distance was observed in the fungal growth in PDA containing at $200 \mathrm{mg} \mathrm{L}^{-1}$. These results are important to choose of fungal isolates with high capacity of absorb, accumulate and transform selenium inorganic into organic. 


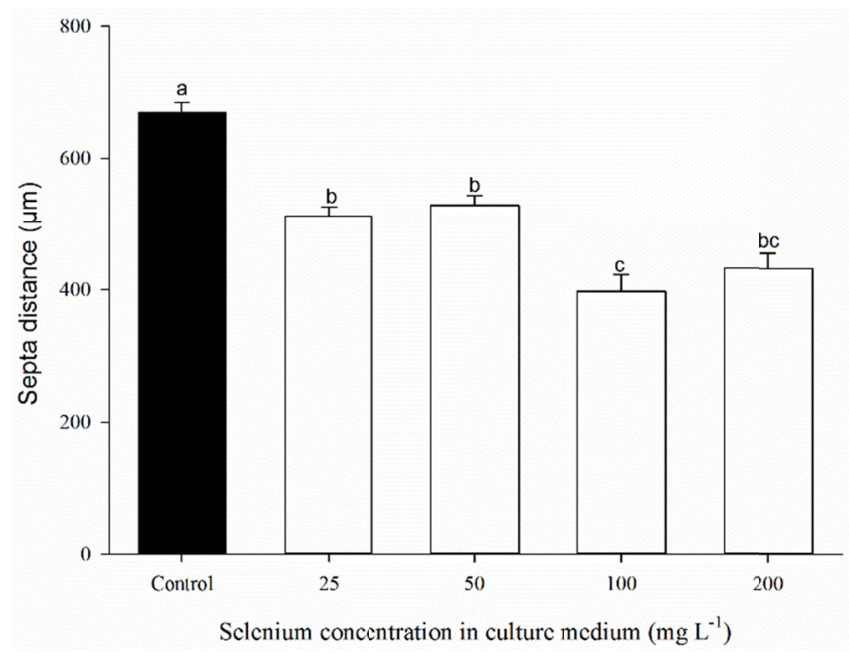

Figure 5. Septa distance of Pleurotus ostreatus cultivated in culture medium containing 0.0 (control), $25,50,100$ and $200 \mathrm{mg} \mathrm{L}^{-1}$ of Se in the forms of sodium selenate $\left(\mathrm{Na}_{2} \mathrm{SeO}_{4}\right)$.

Means followed by different letters differ at Tukey's test $(\mathrm{p}<0.05)$

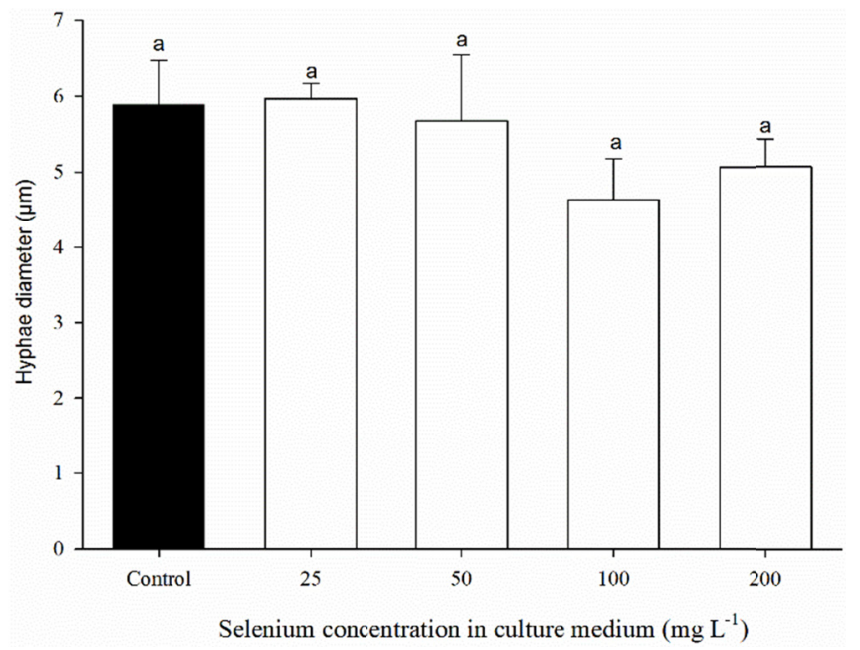

Figure 6. Hyphae diameter of Pleurotus ostreatus cultivated in culture medium containing 0.0 (control), $25,50,100$ and $200 \mathrm{mg} \mathrm{L}^{-1}$ of $\mathrm{Se}$ in the forms of sodium selenate $\left(\mathrm{Na}_{2} \mathrm{SeO}_{4}\right)$.

Means followed by different letters differ at Tukey's test $(\mathrm{p}<0.05)$

\section{Conclusions}

The sodium selenite is more indicated to enrichment of $P$. ostreatus mushrooms than other selenium forms analyzed, due to highest Se accumulation in the mycelium. The changes of colony in color and morphology can be a fungal mechanism to tolerate high Se concentration.

\section{Acknowledgements}

The authors are grateful for the financial, scientific and structural support of CNPQ, FAPEMIG, and FUNARBE. This study was financed in part by the Coordenação de Aperfeiçoamento de Pessoal de Nível Superior-Brasil (CAPES)-Finance Code 001.

\section{References}

Amouroux, D., Pécheyran, C., \& Donard, O. F. X. (2000). Formation of volatile selenium species in synthetic seawater under light and dark experimental conditions. Appl. Organomet. Chem., 14, 236-244. https://doi.org/10.1002/(SICI)1099-0739(200005)14:5\%3C236::AID-AOC982\%3E3.0.CO;2-U

Azevedo, S., Cunha, L. M., \& Fonseca, S. C. (2012). Importância da utilização de cogumelos na alimentação humana. Revista Técnico-científica Agrícola, 2. 
Da Silva, M. C. S., Naozuka, J., da Luz, J. M. R., Assunção, L. S., Oliveira, P. V., Vanetti, M. C. D., ... Kasuya, M. C. M. (2012). Enrichment of Pleurotus ostreatus mushrooms with selenium in coffee husks. Food Chem., 131, 558-563. https://doi.org/10.1016/j.foodchem.2011.09.023

Da Silva, M. C., Nunes, M. D., da Luz, J. M. R., \& Kasuya, M. C. M. (2013). Mycelial Growth of Pleurotus Spp. in Se-Enriched Culture Media. Adv. Microb., 3(11), 18. https://doi.org/10.4236/aim.2013.38A003

De Assunção, L. S., Luz, J. M. R., Silva, M. C. S., Vieira, P. A. F., Bazzolli, D. M. S., Vanetti, M. C. D., \& Kasuya, M. C. M. (2012). Enrichment of mushrooms: An interesting strategy for the acquisition of lithium. Food Chem., 134, 1123-1127. https://doi.org/10.1016/j.foodchem.2012.03.044

De Assunção, L., Silva, M., Fernandez, M., García-Barrera, T., Goméz-Ariza, J. L., Bautista, J., \& Kasuya, M. (2014). Speciation of selenium in Pleurotus ostreatus and Lentinula edodes mushrooms. J. Biotechnol. Lett., 5, 079-086.

Falandysz, J. (2008). Selenium in edible mushrooms. J. Environ. Sci. Health C Environ. Carcinog. Ecotoxicol. Rev., 26(3), 256-299. https://doi.org/10.1080/10590500802350086

Fang, Y., Zhang, Y., Wang, M., Pei, F., Xie, M., Li, P., \& Hu, Q. (2018). In vitro bioaccessibility and speciation changes of selenium in Pleurotus eryngii during the growing stage. Food Funct. https://doi.org/10.1039/ C8FO00566D

Ferreira, K. S., Gomes, J. C., Bellato, C. R., \& Jordão, C. P. (2002). Concentrações de selênio em alimentos consumidos no Brasil. Rev. Panam. Salud. Publica./Pan. Am. J. Public. Health, 11(3). https://doi.org/ 10.1590/S1 020-49892002000300006

Furlani, R. P. Z., \& Godoy, H. T. (2007). Nutritional value of edible mushrooms. Food Sci. Tech., 27(1), 154-157. https://doi.org/10.1590/S0101-20612007000100027

Hu, T., Liang, Y., Zhao, G., Wu, W., Li, H., \& Guo, Y. (2018). Selenium Biofortification and Antioxidant Activity in Cordyceps militaris Supplied with Selenate, Selenite, or Selenomethionine. Biol. Trace Elem. Res. https://doi.org/10.1007/s12011-018-1386-y

Kane, F. C., Tounkara, L. S., Kimassoum, D., Guewo-Fokeng, M., Diop, A. T., \& Mbacham, W. F. (2017). Nutritional value of a dietary supplement of Moringa oleifera and Pleurotus ostreatus. Afr. J. Food Sci., 11(6), 171-177. https://doi.org/10.5897/AJFS2016.1545

Manzi, P., Aguzzi, A., Vivanti, V., Paci, M., \& Pizzoferrato L. (1999). Mushrooms as a source of functional ingredients (Vol. 1, pp. 89-93). Euro. Food Chem. X European Conference on Functional foods: A New Challenge for the Food Chemist, 22-24 September, Budapest, Hungary.

Milovanovic, I., Breski, I, Stajic, M., Korac, A., Vukojevic, J., \& Knezevic, A. (2014). Potential of Pleurotus ostreatus Mycelium for Selenium Absorption. Sci. World J. https://doi.org/10.1155/2014/681834

Nunes, R. G. F. L., da Luz, J. M. R., Freitas, R. B., Higuchi, A., Kasuya, M. C. M., \& Vanetti, M. C. D. (2012). Selenium bioaccumulation in shiitake mushrooms: A nutritional alternative source of this element. J. Food Sci., 77, c983-c986. https://doi.org/10.1111/j.1750-3841.2012.02837.x

Rayman, M. P. (2000). The importance of selenium to human health. Lancet, 356(9225), 233-41. https://doi.org/ 10.1016/S0140-6736(00)02490-9

Silva, M. C. S., Naozuka, J., Oliveira, P. V., Vanetti, M. C. D., Bazzolli, D. M. S., Costa, N. M. B., \& Kasuya, M. C. M. (2010). In vivo bioavailability of selenium in enriched Pleurotus ostreatus mushrooms. Metallomics, 2, 162-166. https://doi.org/10.1039/b915780h

Solovyev, N., Prakash, N. T., Bhatia, P., Prakash, R., Drobyshev, E., \& Michalke, B. (2018). Selenium-rich mushrooms cultivation on a wheat straw substrate from seleniferous area in Punjab, India. J. Trace Elem. Med. Bio., 50, 362-366. https://doi.org/10.1016/j.jtemb.2018.07.027

Sors, T. G., Ellis, D. R., Na, G. N., Lahner, B., Lee, S., Leustek, T., Pickering, I. J., \& Salt, D. E. (2005). Analysis of sulfur and selenium assimilation in Astragalus plants with varying capacities to accumulate selenium. Plant J., 42(6), 785-97. https://doi.org/10.1111/j.1365-313X.2005.02413.x

Sylvia, D. M., Fuhrmann, J. J., Hartel, P. G., \& Zuberer, D. A. (1999). Principles and applications of soil microbiology (pp. 218-258). Prentice Hall: Englewood Cliffs, NJ.

Viaro, R. S., Viaro, M. S., \& Fleck, J. (2001). The biochemical importance of selenium to the human organism. Disciplinarum Scientia. Ciên. Biol. Saúde, 2(1), 17-21. 
Vieira, P. A. F., Gontijo, D. C., Vieira, B. C., Fontes, E. A., De Assunção, L. S., Leite, J. P. V., \& Kasuya, M. C. M. (2013). Antioxidant activities, total phenolics and metal contents in Pleurotus ostreatus mushrooms enriched with iron, zinc or lithium. LWT-Food Sci. Technol., 54, 421-425. https://doi.org/10.1016/j.lwt.20 13.06.016

Zhang, L., \& Chasteen, T. G. (1994). Amending cultures of selenium-resistant bacteria with dimethyl selenone. Appl. Organomet. Chem., 8, 501-508. https://doi.org/10.1002/aoc.590080602

\section{Copyrights}

Copyright for this article is retained by the author(s), with first publication rights granted to the journal.

This is an open-access article distributed under the terms and conditions of the Creative Commons Attribution license (http://creativecommons.org/licenses/by/4.0/). 